\title{
Typology of the countries of Central and Eastern Europe including the CIS: features of the use of alternative energy
}

\author{
Sandra Jednak ${ }^{1,}{ }^{*}$, Olga Shuvalova $^{2}$, and Irina Rodionova ${ }^{1}$ \\ ${ }^{1}$ University of Belgrade, Faculty of Organizational Sciences, Studentski trg, 1, 11000 Belgrade, \\ Serbia \\ ${ }^{2}$ Peoples' Friendship University of Russia (RUDN University), 6 Miklukho-Maklaya Street, Moscow, \\ 117198, Russian Federation
}

\begin{abstract}
The article describes the features of the current state and future development of renewable energy without taking into account the use of water resources in the countries of Central and Eastern Europe (CEE) and European Commonwealth of Independent States (CIS) countries (except Russia). The energy economy of the observed countries varies significantly in structure and total energy consumption, as well as in the degree and structure of alternative energy sources. The study was based on energy statistics (IRENA, UN Statistics Division. REN21, BP, IEA), etc. The purpose of the paper is to propose a typology of countries according to the level of alternative energy development based on an analysis of the existing conditions for pursue of such innovative energy policy. It is shown that the two different types of countries are distinguished. The first type is the more industrially developed countries, but alternative energy is relatively poorly developed in them. The second type is the agro-industrial countries. But they have higher rates of energy production using alternative energy sources per unit of GDP.
\end{abstract}

\section{Introduction}

The alternative and renewable energies get in focus due to the benefits of their use. Those energies influence on obtaining sustainable development, preventing climate changes, reduction in emitting greenhouse gases, diversity of energy supplies and creating jobs [1]. The Renewables Global Status Report (GSR) is the report of the renewable energy market, industry, and policy trends. A global policy network [2] provides a forum for international leadership on renewable energy. Its goal is to bolster policy development for the rapid expansion of renewable energies in developing and industrialized economies $[2 ; 3 ; 4]$. Alternative energy development is the aim of various countries. The EU Member States have national renewable energy action plans 2020 in order to fulfilled Europe 2020 strategy`s target a $20 \%$ share of energy from renewable sources [5]. Following more developed EU countries, the national energy development programs of all CEE countries

\footnotetext{
*Corresponding author: dvigh@mail.ru
} 
(both EU and non-EU) also set the task of increasing the share of renewable energy sources in the Energy balance.

The economic and legal issues of the use of renewable energy sources are an issue in various papers $[6 ; 7 ; 8 ; 9]$. Also, different countries have their policy of energy development. For example, besides highly developed countries, China also pays very significant attention to the development of alternative and renewable energy in its energy policy $[10 ; 11 ; 12]$. Furthermore, there are papers devoted to forecasting the development of the industry, analysing the use of alternative energy sources in specific regions and countries $[13 ; 14 ; 15]$.

It should be noted the individual CIS countries have significant energy resources. Even so, these countries are not always and entirely given the attention to the development of alternative energy sources $[3 ; 4]$.

The paper research presented is driven by the following research questions: Are there associations exist between the level of alternative energy use and the features of the energy supply in the observed countries? Does the level of industrialization influence alternative energy development? Are there conditions for the further development of alternative energy? Does the common European Union energy policy promote development of the alternative energy use in observed countries?

Besides these research questions, an analysis of the factors affecting the energy sector development in the observed countries is allowed the authors to put a hypothesis.

The first hypothesis answers the question about the role in energy efficiency at the level of development of alternative energy.

The second hypothesis is than the more industrialized countries of the CEE and European CIS region are less interested in using alternative energy sources (AES) than the less developed or developing ones (industrial-agrarian and agrarian-industrial).

So, the purpose of the paper is to propose a typology of countries according to the level of alternative energy development based on an analysis of the existing conditions for pursue of such innovative energy policy.

\section{Materials and Method}

The situation is analysed in 19 countries - the CEE countries (Poland, Slovakia, Czech Republic, Hungary, Slovenia, Croatia, Bosnia and Herzegovina, Serbia, Montenegro, Albania, Macedonia, Bulgaria, Romania, Estonia, Latvia and Lithuania) and the European CIS countries (Ukraine, Belarus, Moldova). Russia (as noted above) is excluded from the analysis. Initially, statistic data that were analysed are the structure of the energy balance and the structure of alternative energy balance thinking about certain types of alternative energy (wind energy, solar energy, biofuel, etc.). The authors analysed available data on the value of energy use in observed countries.

The following research methods are used: comparative, analytical, mathematicalstatistical, multi-attribute classification, and cartography. The results are presented by tables, diagrams, and cartography. Following the multi-attribute classification methodology, the authors have compiled the ranking and, on its basis, elaborated the typology of CEE and European CIS countries (except for Russia) by the level of the alternative energy development.

We understand that alternative energy in CEE countries is generally less developed than in Western Europe countries. Their potential has not yet been revealed and these countries need to be investigated in a special way. We understand that there are certain conditions for the future development of alternative energy in these countries. The question was what kind of conditions are these - different self-sufficiency of the economy with energy resources or something else. 
In our analysis, we realized that there are 4 indicators that are interconnected. Among them are: Total Alternative Energy Supply per GDP unit, GDP per capita, calculated the «Level of industrialization», Share of Manufacturing Value Added in GDP (\%). The standard formula for correlation coefficients is used and it is calculated in the Excel program. Thereby we found that the success of alternative energy development is inversely proportional to the degree of industrial development. We took as a factor or condition for the successful development of alternative energy - the presence, or rather the absence of a manufacturing industry.

The author's indicator called "The Level of industrialisation" is calculated as the ratio of the share of a country in the creation of world manufacturing products to the share of the same country in the world population. In other words, this indicator shows the role of each country in the global manufacturing industry. The estimated indicator will be above one for industrialized countries and below one for less developed countries.

The final rating of the countries (to calculate the conglomerate-indicator) is obtained by ranking by selected indicators. For each indicator (criteria), the country`s rank is determined (position in the general list from the highest to the lowest importance for successful alternative energy development - from 1 to 19). To obtain the values in the final table, the countries` ranks for each indicator are summarized. Thus, the leaders of the rating list received the least points, and outsiders - the maximum.

Authors used materials on energy [16, 17].

\section{Results}

Studying statistics on the use of alternative energy sources in the countries of CentralEastern Europe and the European CIS, we found an interesting fact, an anomaly. In peripheral countries, the most distant from Western Europe, there is an increased role of alternative energy in the economy, including in terms of energy supply per unit of GDP (figure 1). It is the first statement.

The most significant successes in the alternative energy development in the post-Soviet space were achieved by the Baltic States (Lithuania, Latvia, Estonia), including in such indicators as the Total energy supply per GDP. Good relative indicators are shown by Moldova, Ukraine, Croatia, Bosnia and Herzegovina, and Montenegro. Serbia, Belarus and Bulgaria are developing well alternative energy. On the contrary, the neighbors of Austria and Germany, in which alternative energy is actively developing, show very modest results in this innovative area. Among them are Poland, Czech Republic, Hungary, Slovenia, Slovakia, as well as and Romania, Albania and Macedonia.

Subsequently, when we found common ground in the development of alternative energy in these countries, it was confirmed that these groups of countries correspond to two types. It is the second statement. The main similar conditions of these are listed below.

We tried to explain the fact of a more developed alternative energy in the peripheral countries with some other, additional arguments besides the lack of neighbourhood with Western Europe. On the contrary, the neighbourhood of CEE countries with Western Europe countries should have the opposite effect - alternative energy in these countries should be guaranteed to develop rapidly.

As we mentioned above, the first hypothesis was possible differences in countries' selfsufficiency in energy resources, the structure of suppliers, and the structure of the fuel and energy balance. 


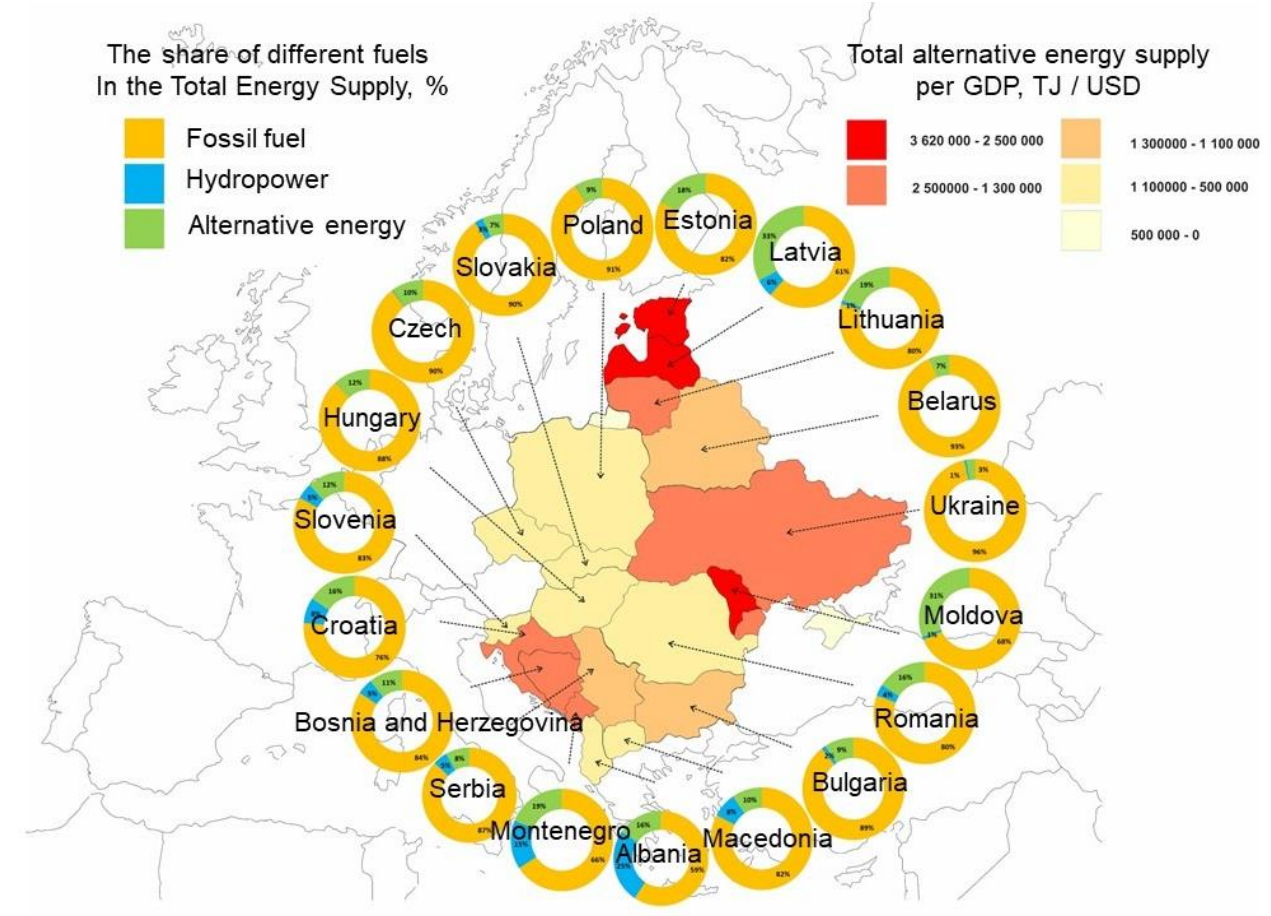

Fig. 1. The structure of Energy Balance versus the value of alternative energy supply per GDP in the CEE and European CIS countries, 2016

Source: Calculated by the authors $[16,17]$

There is no critical relationship between structure of Energy Balance and the development of alternative energy.

As for self-sufficiency, the conclusion suggests itself that - among the CEE countries and European CIS countries there are no countries that are completely self-sufficient in energy resources. A lot of resources are imported. This indicator does not show differences between these countries.

To answer the last not least research question (second hypothesis) does the correlation exist between the level of use of AES and basic economic indicators standard formula for correlation coefficients is used. The more industrialized countries of the CEE and European CIS region are less interested in the development of alternative energy than the less developed (industrial-agrarian) ones. It is the third statement.

\section{Discussion}

A study of the energy policies of the countries of observed countries this region in the field of alternative energy development led out to the understanding that each country (especially with modest financial opportunities and available recourses) is trying to implement costeffective alternative energy development programs. At a low cost from the budget of the country, they do not cause public protest.

The authors concluded that to characterize the effectiveness of energy policy in the field of alternative energy development, the relative indicators such as the alternative energy supply per GDP are most suitable.

However, this fact also indicates that investment-costly alternative energy development programs in the CEE EU member states are less productive than technological programs 
that are implemented in the outlying ("peripheral) EU countries with more modest financial capabilities. In these countries, the emphasis is on the use of AES, which do not require expensive high-tech solutions for their production.

The renewable energy is a key topic in different fields like development, production and policy. Further research work might have a few targets:

- to analyse the structure of alternative energy balance according to sources (wind, solar, etc.).

- to study the level of liberalisation of electricity markets in different countries of EEC and European CIS, because the growth of alternative energy use forces the increase of new suppliers on the market.

\section{Conclusion}

The analysis made it possible to characterize the current stage in the development of energy policy in the space of CEE countries and European CIS countries (except Russia). Currently, almost all of these countries are not adequately provided with their resources of hydrocarbon raw materials for the development of energy. They are forced to import energy and to improve the situation they are forced to develop alternative energy.

The study showed that two types of countries of the analysed region could be distinguished. Some countries are more industrialized (industrial states). At the same time, they have a high level of energy consumption. But in the alternative energy is still poorly developed. We considered them to be a separate type of countries. Among them are Poland, Czech Republic, Hungary, Slovenia, Slovakia, Romania, Albania and Macedonia.

Other countries have relatively high rates of energy production using renewable energy sources, but in general, they can be attributed to agrarian-industrial or industrial-agrarian states. Among them are Lithuania, Latvia, Estonia, Moldova, Ukraine, Croatia, Bosnia and Herzegovina, Montenegro. Serbia, Belarus, Bulgaria. They belong to the second type of country.

\section{Acknowledgment}

This paper has been supported by the RUDN University Strategic Academic Leadership Program.

\section{References}

1. European Commission Renewable energy statistics (2020)

2. REN21 Renewables 2019 Global Status Report. Perspectives on the Global Renewable Energy Transition (2019)

3. United Nations Development Program (UNDP) Sustainable Energy and Human Development in Europe and the CIS (New York, 2014)

4. UN Economic Commission for Europe Energy Efficiency 21: Project Plan 2012-2015 (2012)

5. Directive 2009/28/EC of the European Parliament and of the Council of 23 April 2009 on the promotion of the use of energy from renewable sources and amending and subsequently repealing Directives 2001/77/EC and 2003/30/EC. (2009)

6. O.V. Shuvalova, M.V. Chernyaev, I.A. Rodionova, A.V. Korenevskaya, International Journal of Energy Economics and Policy, 8(4), 199 (2018) 
7. N. Anglani, G. Muliere, International Journal of Energy and Environmental Engineering, 2(5), 83 (2011)

8. A. Lombard, S.LA. Ferreira, Bulletin of Geography. Socio-economic Series, 30(30), 71 (2015)

9. B. Paulos, On Biofuels, Part 1: Dispelling myths about biopower. (The Energiwende Blog, 2017)

10. Y.Li, D. Nie, X. Zhao, Renew. Sustain. Energy Rev. , 70, 78 (2017)

11. J. Liu Renew. Sustain. Energy Rev., 99, 212 (2019)

12. Y. Zhao, X. Liu, S. Wan, Y. Ge, Renewable \& Sustainable Energy Reviews, 107, 133 (2019)

13. E.A. Antipova, L.O. Zhigalskaya, I.A. Rodionova, M.V. Chernyaev, Journal of Environmental Management and Tourism, 8(5), 1101 (2017)

14. C. Croonenbroeck, G. Stadtman, Renewable \& Sustainable Energy Reviews, 108, 312 (2019)

15. N. Mararakanye, B. Bekker, Renewable \& Sustainable Energy Reviews, 108, 441 (2019)

16. International Renewable Energy Agency. IRENA Database (2016)

17. United Nations Statistics Division (2018) 